\title{
Islet amyloid formation is an important determinant for inducing islet inflammation in high-fat-fed human $I A P P$ transgenic mice
}

\author{
Daniel T. Meier • Mary Morcos • Thanya Samarasekera • \\ Sakeneh Zraika • Rebecca L. Hull • Steven E. Kahn
}

Received: 1 February 2014 / Accepted: 28 May 2014 / Published online: 26 June 2014

(C) Springer-Verlag (outside the USA) 2014

\begin{abstract}
Aims/hypothesis Amyloid deposition and inflammation are characteristic of islet pathology in type 2 diabetes. The aim of this study was to determine whether islet amyloid formation is required for the development of islet inflammation in vivo. Methods Human islet amyloid polypeptide transgenic mice and non-transgenic littermates (the latter incapable of forming islet amyloid) were fed a low-fat (10\%) or high-fat (60\%) diet for 12 months; high-fat feeding induces islet amyloid formation in transgenic mice. At the conclusion of the study, glycaemia, beta cell function, islet amyloid deposition, markers of islet inflammation and islet macrophage infiltration were measured.

Results Fasting plasma glucose levels did not differ by diet or genotype. Insulin release in response to i.v. glucose was significantly greater in both high vs low fat groups, and significantly lower in both transgenic compared with nontransgenic groups. Only high-fat-fed transgenic mice developed islet amyloid and showed a trend towards reduced beta cell area. Compared with islets from low-fat-fed transgenic or high-fat-fed non-transgenic mice, islets of high-fat-fed transgenic mice displayed a significant increase in the expression of genes encoding chemokines ( $\mathrm{Ccl} 2, \mathrm{Cxcl})$, macrophage/ dendritic cell markers (Emrl, Itgax), NACHT, LRR and PYD
\end{abstract}

Electronic supplementary material The online version of this article (doi:10.1007/s00125-014-3304-y) contains peer-reviewed but unedited supplementary material, which is available to authorised users.

D. T. Meier $(\bowtie) \cdot$ M. Morcos $\cdot$ T. Samarasekera $\cdot$ S. Zraika

R. L. Hull • S. E. Kahn

VA Puget Sound Health Care System (151), 1660 S. Columbian Way, Seattle, WA 98108, USA

e-mail: meierdan@uw.edu

D. T. Meier $\cdot$ M. Morcos $\cdot$ T. Samarasekera $\cdot$ S. Zraika $\cdot$ R. L. Hull $•$

S. E. Kahn

Division of Metabolism, Endocrinology and Nutrition, Department of Medicine, University of Washington, Seattle, WA, USA domains-containing protein 3 (NLRP3) inflammasome components (Nlrp3, Pycard, Casp1) and proinflammatory cytokines (Illb, Tnf, Il6), as well as increased F4/80 staining, consistent with increased islet inflammation and macrophage infiltration.

Conclusions/interpretation Our results indicate that islet amyloid formation is required for the induction of islet inflammation in this long-term high-fat-diet model, and thus could promote beta cell dysfunction in type 2 diabetes via islet inflammation.

Keywords Chemokine $\cdot$ Cytokine $\cdot$ In vivo $\cdot$ Insulin secretion $\cdot$ Macrophage $\cdot$ NLRP3 inflammasome

$\begin{array}{ll}\text { Abbreviations } \\ \text { AIRg } & \text { Acute insulin response to glucose } \\ \text { CASP1 } & \text { Caspase 1 } \\ \text { CCL2 } & \text { Chemokine (C-C motif) ligand 2 } \\ \text { CXCL1 } & \text { Chemokine (C-X-C motif) ligand 1 } \\ \text { HF } & \text { High-fat-fed } \\ \text { hIAPP } & \text { Human islet amyloid polypeptide } \\ \text { LF } & \text { Low-fat-fed } \\ \text { NLRP3 } & \text { NACHT, LRR and PYD domains-containing } \\ & \text { protein 3 }\end{array}$

\section{Introduction}

Amyloid deposition [1] and inflammation [2] are both characteristics of the islet in type 2 diabetes. In humans with this disease, amyloid is associated with beta cell loss [3], while blockade of the proinflammatory cytokine IL-1 $\beta$ results in improved beta cell function and glucose tolerance [4]. Recent studies suggest that the unique peptide constituent of amyloid deposits, human islet amyloid polypeptide (hIAPP), is capable 
of activating macrophages in vitro, resulting in increased expression of IL- $1 \beta$, IL- $1 \alpha$ and TNF- $\alpha[5,6]$. However, a relatively short-term in vivo study reported that high fat feeding in hIAPP transgenic mice only increased islet IL- $1 \beta$ expression [7]. The aim of this study was to determine whether islet amyloid formation is required for the development of islet inflammation in vivo using a mouse model of islet amyloid formation.

\section{Methods}

Transgenic mice Male hemizygous transgenic mice with beta cell expression of hIAPP [8] on a F1 C $57 \mathrm{BL} / 6 \times \mathrm{DBA} / 2$ background were used with non-transgenic littermates as controls. Transgenic mice (C57BL/6) were bred with DBA/2 mice obtained from Jackson Laboratories (Bar Harbor, ME, USA). The study was approved by the Institutional Animal Care and Use Committee at VA Puget Sound Health Care System (VASPHCS).

Groups and diets At 8-10 weeks of age, mice were randomly assigned to receive diets containing either $10 \%$ (low fat) or $60 \%$ (high fat) of energy derived from fat for 12 months (Research Diets, New Brunswick, NJ, USA). The mice had free access to food and water throughout the study.

\section{Metabolic measurements and body composition Body weight} was measured at baseline and every 4 weeks thereafter. At 12 months, a subset of mice underwent an overnight fast followed by an IVGTT ( $1 \mathrm{~g} / \mathrm{kg}$ dextrose) under pentobarbital sodium anaesthesia. Blood samples were drawn before and 2 and $5 \mathrm{~min}$ after glucose injection. The acute insulin response to glucose (AIRg) was calculated as the mean incremental insulin response above baseline from 2 to $5 \mathrm{~min}$ after glucose administration. Before the mice were killed, fat and lean mass was determined in 6-12 mice per group by proton magnetic resonance spectroscopy under pentobarbital anaesthesia.

Assessment of islet morphology Quantification of amyloid area/islet area and beta cell area/islet area was performed on formalin-fixed, paraffin-embedded pancreas specimens labelled with thioflavin $\mathrm{S}$ to visualise amyloid deposits and insulin antibody to visualise beta cells [8] (for further details of antibodies used, please see ESM Table 1). Total islet, amyloid and beta cell areas were calculated using a computer-based quantitative method [8]. Slides were treated with proteinase $\mathrm{K}$ for $15 \mathrm{~min}$, stained with an $\mathrm{F} 4 / 80$ antibody (ESM Table 1), scanned in brightfield and analysed using Visiopharm Image Analysis, version 4.5.6.440 (Visiopharm, Hoersholm, Denmark). Islets were outlined manually and F4/80-positive area calculated using a project-specific configuration based on a threshold of pixel values.
Islet isolation and RNA quantification Pancreatic islets were isolated as described previously [9]. RNA was isolated, reverse transcribed and gene expression determined by TaqMan real-time quantitative PCR using the primers listed in ESM Table 2. Each sample was run in triplicate, normalised to eukaryotic 18S rRNA and results calculated using the $\Delta \Delta \mathrm{C}_{\mathrm{t}}$ method [9].

Statistical analysis Data are presented as mean \pm SEM. Statistical significance was determined using the MannWhitney $U$ test. A $p$ value $\leq 0.05$ was considered statistically significant.

\section{Results}

Body weight, body fat content, plasma glucose and insulin responses Body weight at baseline did not differ between low-fat-fed (LF) non-transgenic $(29.7 \pm 0.7 \mathrm{~g})$, LF transgenic $(28.1 \pm 0.7 \mathrm{~g})$, high-fat-fed $(\mathrm{HF})$ non-transgenic $(29.7 \pm 0.6 \mathrm{~g})$ and HF transgenic $(29.9 \pm 0.8 \mathrm{~g})$ mice. The body weight in all groups increased over the 12 months of study, with the increase being greater in HF mice, regardless of genotype (Fig. 1a). The proportion of body weight consisting of fat was significantly higher in HF mice, with no difference between genotypes (Fig. 1b).

Neither fed nor fasting (Fig. 1c) plasma glucose levels differed by diet or genotype at 12 months. Fasting plasma insulin levels were greater in HF non-transgenic (1329.5 \pm $255.1 \mathrm{pmol} / \mathrm{l})$ and HF transgenic $(2654.1 \pm 1116.3 \mathrm{pmol} / \mathrm{l})$ mice compared with both LF groups (non-transgenic: $125.4 \pm 21.2 \mathrm{pmol} / \mathrm{l}$; transgenic: $134.7 \pm 29.6 \mathrm{pmol} / \mathrm{l}) . \mathrm{AIRg}$ was significantly greater in both the HF vs LF groups (Fig. 1d), and in non-transgenic compared with transgenic groups fed the same diet (Fig. 1d).

Islet morphology Non-transgenic mice on both diets and LF transgenic animals did not develop islet amyloid. In contrast, $80 \%$ of HF transgenic animals developed islet amyloid, with $7.3 \pm 2.6 \%$ of islet area occupied by amyloid (Fig. 1e). Beta cell/islet area was not different between the LF groups, but tended to be decreased in HF transgenic vs HF non-transgenic mice $(p=0.07)$ (Fig. 1f).

F4/80-positive/islet area was significantly elevated in $\mathrm{HF}$ transgenic mice vs LF transgenic and HF non-transgenic animals (Fig. 2a-d). Compared with islets from LF nontransgenic mice, F4/80-positive/islet area was also increased in islets of LF transgenic and HF non-transgenic mice.

Islet gene expression of inflammation-related molecules As illustrated in Fig. 2e, compared with HF non-transgenic mice, $\mathrm{HF}$ transgenic mice had significantly increased islet 

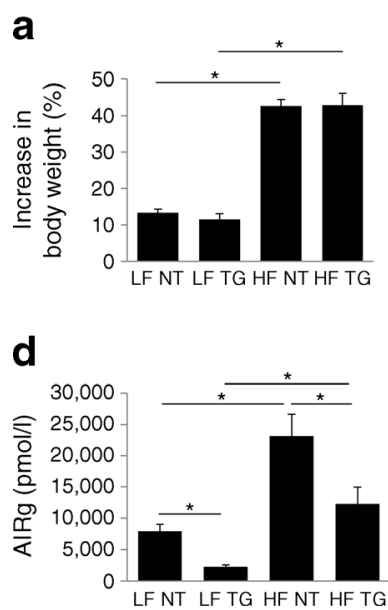

e

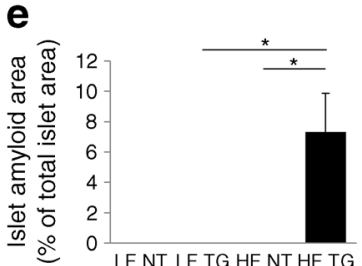

C
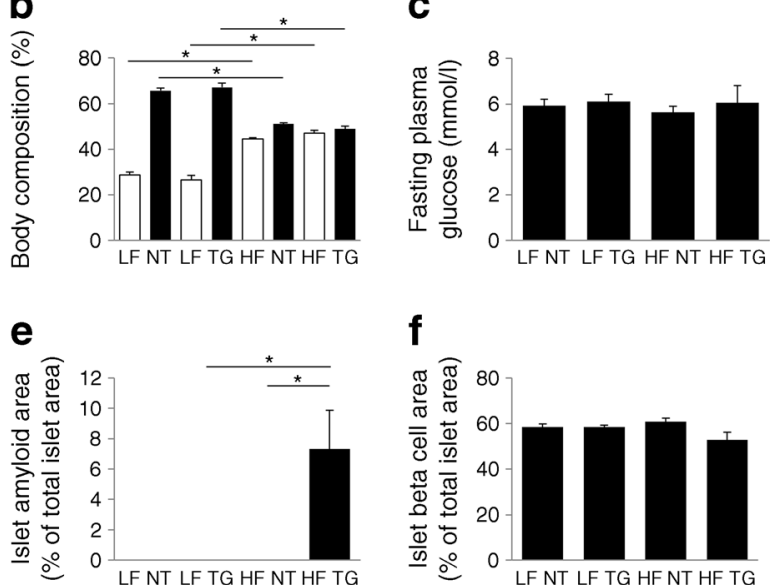

Fig. 1 Body weight increase (a), body composition (b), fasting plasma glucose (c), AIRg (d), islet amyloid area (e) and islet beta cell area (f) of LF and HF non-transgenic (NT) and $\mathrm{h} I A P P$ transgenic (TG) mice after being on the diets for 12 months. In (b) the white bars represent fat mass and the black bars represent fat-free mass. Sample sizes for panels (a), (b) and (c) are 12 LF NT, 10 LF TG, 6 HF NT, 10 HF TG; for panel (d) are 10 LF NT, 9 LF TG, 6 HF NT, 9 HF TG; and for panels (e) and (f) are 12 LF NT, 8 LF TG, 6 HF NT, 10 HF TG. ${ }^{*} p \leq 0.05$ expression of genes encoding the chemokines known as chemokine (C-C motif) ligand 2 (CCL2) and chemokine (C-X-C motif) ligand 1 (CXCL1), macrophage/dendritic cell markers F4/80 (also known as EGF-like module-containing mucinlike hormone receptor-like 1, EMR1) and CD11c (also known as integrin alpha $\mathrm{X}$, ITGAX), inflammasome components NACHT, LRR and PYD domains-containing protein 3 (NLRP3), PYD and CARD domain containing (PYCARD) and caspase 1 (CASP1), as well as proinflammatory cytokines IL- $1 \beta$, TNF- $\alpha$ and IL-6. In addition, compared with LF transgenic mice, HF transgenic mice had significantly increased islet expression of genes encoding CCL2, CXCL1, F4/80, CD11c, CASP1, IL-1 $\beta$, TNF- $\alpha$ and IL-6. In contrast, there were no significant differences in the expression of these same genes in LF vs HF non-transgenic mice and transgenic vs non-transgenic mice on the low-fat diet. a

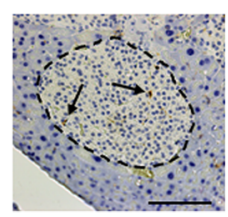

b

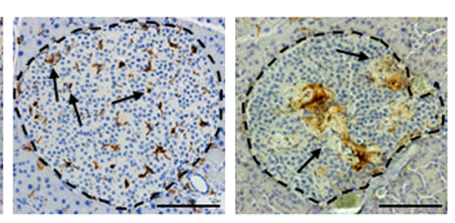

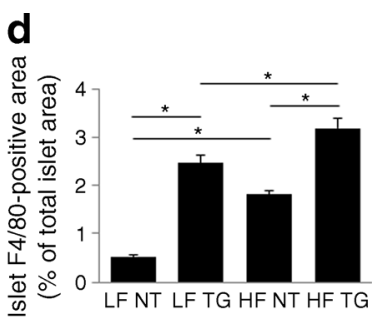

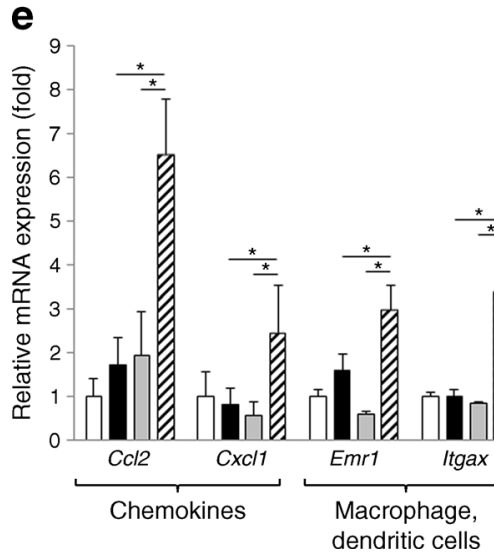

Fig. 2 Islet inflammation at the end of the 12-month diet intervention. Images of F4/80 staining (denoted by arrows) of islets (outlined by dashed lines) with low (a), medium (b) or high (c) degrees of staining. Scale bar, $100 \mu \mathrm{m}$. (d) Proportion of F4/80 macrophage staining in islets of LF and HF non-transgenic (NT) and hIAPP transgenic (TG) mice. An average of 355 islets from six mice for each group were analysed. (e)
mRNA expression in islets isolated from LF non-transgenic (white bars), LF hIAPP transgenic (black bars), HF non-transgenic (grey bars), and HF $\mathrm{h} I A P P$ transgenic (hatched bars) groups of mice at the end of the 12 -month diet intervention. Values were normalised to $18 \mathrm{~S}$ rRNA and then expressed as fold relative to the mRNA expression in LF non-transgenic mice ( $n=5-8$ per group). ${ }^{*} p \leq 0.05$ 


\section{Discussion}

We have observed that islet amyloid formation is associated with increased islet expression of mRNAs for chemokines, macrophage/dendritic cell markers, NLRP3 inflammasome components, and proinflammatory cytokines, along with increased staining of macrophages. Thus, our findings emphasise the important role of amyloid in islet inflammation.

After 12 months of being fed a high-fat diet, in the transgenic mice we observed islet amyloid formation and increased expression of genes encoding chemokines ( $\mathrm{Ccl} 2$ and $\mathrm{Cxcl1}$ ), macrophage and dendritic cell markers (Emrl and Itgax), components of the NLRP3 inflammasome (Nlrp3, Pycard, Casp1), and proinflammatory cytokines (Illb, Tnf and IlO). In contrast, none of these changes were observed in nontransgenic mice on the high-fat diet or transgenic mice on the low-fat diet, in keeping with amyloid formation being the mechanism by which these inflammatory changes occurred. We also observed increased macrophage staining in islets of HF transgenic mice, consistent with amyloid deposition being associated with an increased number of activated macrophages. These findings are consistent with, but expand on, those of Westwell-Roper et al [7]. In their hIAPP transgenic mice fed a high-fat diet for 14 weeks they did not observe amyloid deposition, and only observed increases in Emrl, Nlrp3 and Illb compared with non-transgenic mice on the same diet. In addition, in these same $\mathrm{h} I A P P$ transgenic mice they did not observe increases in Ccl2, Casp1, Pycard and Tnf mRNA levels, and did not report on Il6 mRNA levels. In fact, the phenotype we observed is more in keeping with the in vitro observation by Westwell-Roper et al whereby the exogenous application of amyloidogenic hIAPP to islets or macrophages induced expression of Ccl2, Emr1, Nlrp3, Casp1, Il1b, Tnf and Il6 compared with the application of non-amyloidogenic rodent IAPP.

Westwell-Roper also observed an increase in $111 \mathrm{~b}$ expression in $\mathrm{h} I A P P$ transgenic vs non-transgenic mice, both fed a chow diet. We did not observe such a change but found F4/80 staining to be increased and AIRg to be decreased in $\mathrm{h} I A P P$ transgenic mice fed the low-fat diet when visible amyloid was not present. These amyloid-independent effects might be mediated by early/small aggregates of IAPP. Interestingly, the high-fat diet alone also increased the proportion of F4/80positive staining. This suggests that exposure to a high-fat diet or expression of low levels of IAPP recruits macrophages, with the full-blown inflammatory response involving IL- $1 \beta$, IL- 6 and TNF- $\alpha$ requiring greater amounts of amyloid that are visible by light microscopy.

We and others have previously demonstrated that hIAPP application to macrophages and dendritic cells in vitro activates the NLRP3 inflammasome, resulting in the production of the proinflammatory cytokine IL-1 $\beta$ [5-7]. WestwellRoper et al provided evidence that beta cells themselves are not a major source of IL- $1 \beta$ but, rather, islet macrophages are responsible for IL-1 $\beta$ production $[5,7]$. Our observations of increased chemokine gene expression and F4/80 staining suggest that islet amyloid formation is likely associated with the recruitment of macrophages to the islet. The increases in the expression of the genes encoding the proinflammatory cytokines IL- $1 \beta$ and TNF- $\alpha$ are likely to have resulted from the increase in macrophage activation and these, in turn, may also have contributed to the decreased insulin release we observed in $\mathrm{h} I A P P$ transgenic mice that developed islet amyloid. We have previously reported that amyloid deposition in our mouse model is associated with decreased beta cell area [8]. We observed a trend towards reduced beta cell area in our current study ( $p=0.07$ ), and this statistical non-significance is likely to be due to the smaller sample size. Our findings thus suggest that islet inflammation may also contribute to decreased beta cell area.

In conclusion, islet amyloid formation in $\mathrm{h} I A P P$ transgenic mice is associated with inflammation, which may lead to beta cell loss and thus contribute to the progression of the islet lesion in type 2 diabetes.

Acknowledgements We thank B. Barrow, M. Peters, J. Willard, P. Bergquist, C. Braddock and A. Rahman (all Seattle Institute for Biomedical and Clinical Research, Seattle, WA, USA) for excellent technical support.

Funding This work was supported by the Department of Veterans Affairs (SEK), DK-074404 (RLH), DK-080945 (SZ) and DK-017047. DTM was supported by a Swiss National Foundation Fellowship and the University of Washington McAbee Fellowship. TS was supported by an American Diabetes Association Mentor-Based Fellowship.

Duality of interest The authors declare that there is no duality of interest associated with this manuscript.

Contribution statement DTM contributed to the study design, performed research, analysed data and wrote the manuscript. MM performed research, analysed data and reviewed/edited the manuscript. TS helped interpret the data and reviewed/edited the manuscript. SZ, RLH and SEK contributed to the study design, helped interpret the data and reviewed/ edited the manuscript. All authors approved the final version. DTM is responsible for the integrity of the work as a whole.

\section{References}

1. Hull RL, Westermark GT, Westermark P, Kahn SE (2004) Islet amyloid: a critical entity in the pathogenesis of type 2 diabetes. J Clin Endocrinol Metab 89:3629-3643

2. Donath MY, Boni-Schnetzler M, Ellingsgaard H, Halban PA, Ehses JA (2010) Cytokine production by islets in health and diabetes: cellular origin, regulation and function. Trends Endocrinol Metab 21: 261-267

3. Jurgens CA, Toukatly MN, Fligner CL et al (2011) Beta-cell loss and beta-cell apoptosis in human type 2 diabetes are related to islet amyloid deposition. Am J Pathol 178:2632-2640 
4. Larsen CM, Faulenbach M, Vaag A et al (2007) Interleukin-1-receptor antagonist in type 2 diabetes mellitus. N Engl J Med 356:1517-1526

5. Westwell-Roper C, Dai DL, Soukhatcheva G et al (2011) IL-1 blockade attenuates islet amyloid polypeptide-induced proinflammatory cytokine release and pancreatic islet graft dysfunction. J Immunol 187:2755-2765

6. Masters SL, Dunne A, Subramanian SL et al (2010) Activation of the NLRP3 inflammasome by islet amyloid polypeptide provides a mechanism for enhanced IL- $\beta \beta$ in type 2 diabetes. Nat Immunol 11:897-904
7. Westwell-Roper CY, Ehses JA, Verchere CB (2013) Resident macrophages mediate islet amyloid polypeptide-induced islet IL-1 $\beta$ production and beta cell dysfunction. Diabetes 63:1698-1711

8. Hull RL, Andrikopoulos S, Verchere CB et al (2003) Increased dietary fat promotes islet amyloid formation and beta-cell secretory dysfunction in a transgenic mouse model of islet amyloid. Diabetes 52:372-379

9. Zraika S, Hull RL, Udayasankar J et al (2007) Identification of the amyloid-degrading enzyme neprilysin in mouse islets and potential role in islet amyloidogenesis. Diabetes 56:304-310 